\title{
Uso de propriedades físico-hídricas do solo na identificação de camadas adensadas nos Tabuleiros Costeiros, Sergipe
}

\author{
Marcos H. P. Fonsêca ${ }^{1}$, Hugo O. C. Guerra ${ }^{2}$, Rogério D. de Lacerda² \& Aurelir N. Barreto ${ }^{3}$
}

\begin{abstract}
RESUMO
A presença de camadas subsuperficiais no solo fortemente adensadas, afeta a infiltração e o movimento de água dificultando o manejo da água durante a irrigação. Visando identificar e caracterizar essas camadas coesas nos tabuleiros do Platô de Neopolis de Sergipe se determinaram e se utilizaram as propriedades físico-hídricas do solo densidade, porosidade, retenção da água e condutividade capilar. A Condutividade Capilar foi determinada através do método do perfil instantâneo empregando-se o modelo de Libardi. Os atributos físicos determinados (densidade, porosidade, retenção da água e condutividade capilar) mostraram-se adequados à identificação e caracterização do caráter coeso da camada quando presente no perfil do solo.
\end{abstract}

Palavras-chave: adensamento, irrigação, condutividade capilar

\section{Use of soil physico-hydrical characteristics to identify high density layers on a tableland soil at Sergipe}

\begin{abstract}
The presence of subsurface high density soil layers has an important effect upon the infiltration and water movement into the soil, difficulting the water management during the irrigation. Aiming to identify and characterize this high density soil layers at the Neopolis Platô, Sergipe State, Brazil, the physico-hydrical properties density, porosity, water retention and capillary conductivity were determined and utilized. The capillary conductivity was determined throughout the instantaneous soil profile using the Libardi Model. The studied characteristics (density, porosity, water retention and capillary conductivity) were very effective at identifying and characterizing the hardsetting layers.
\end{abstract}

Key words: hardsetting soils, irrigation, capillary conductivity

Rua Arauá, Bairro São José, CEP 57036-060, Aracaju, SE. Fone: (79) 3214-1712. E-mail: mhfonseca@bol.com.br

2 UAEAg/CTRN/UFCG. Av. Aprígio Veloso, 882, CEP 58109-970, Campina Grande, PB. Fone: (83) 3310-1285. E-mail: hugo carvallo@hotmail.com, rogerio_dl@yahoo.com.br

${ }^{3}$ EMBRAPA. Rua Osvaldo Cruz, 1143, Centenário, CEP 58107-720, Campina Grande, PB. Fone: (83) 3315-4358. E-mail: aurelir@cnpa.embrapa.br 


\section{INTRODUÇÃO}

Os Tabuleiros Costeiros são formações terciárias que se formaram no Amapá e que vão até o Rio de Janeiro e são mais freqüentes nas costas do litoral nordestino. A importância deste ecossistema está relacionada não somente ao significativo contingente de população, o qual perfaz cerca de $50 \%$ da região Nordeste, mas, também, por sua utilização com cana-de-açúcar, pecuária e fruticultura. Nos últimos dez anos e com mais ênfase nos dias atuais, a fruticultura, em especial o coqueiro anão-verde, destinado à produção de água de coco, tem ocupado grandes extensões dos tabuleiros, como ocorre no Distrito de Irrigação do Platô de Neópolis. Apesar da atenção voltada para as áreas de tabuleiro, uma das limitações à fruticultura irrigada ainda é a carência de informações sobre as características físico-hídricas dos solos, fundamentais para o estabelecimento de um bom manejo solo-água-planta. Entre as restrições dos Tabuleiros Costeiros, as mais freqüentes dizem respeito às limitações químicas e físicas dos seus solos. Com respeito às restrições químicas, destacam-se a baixa capacidade de troca catiônica, causada por baixos teores de matéria orgânica e a predominância da caulinita na fração argila, enquanto com relação às restrições físicas, uma das mais significativas é a ocorrência de horizontes coesos sub superficiais que, devido ao elevado grau de adensamento, dificultam a infiltração e o transporte de água no perfil do solo, prejudica a aeração e impede o aprofundamento do sistema radicular, que se concentra na camada superficial do solo.

O caráter coeso observado em grande parte dos solos dos Tabuleiros Costeiros abrange aproximadamente dez milhões de hectares, apenas na região do Nordeste Brasileiro (Jacomine, 1996; Rezende, 2000). A presença de horizontes coesos, aliada à distribuição irregular das chuvas da região, é a principal limitação para a obtenção de elevada produtividade das culturas, condições em que a presença de seções coesas e de regime climático com longos períodos de déficit hídrico, resulta em elevada resistência do solo à penetração das raízes, prejudicando o rendimento potencial das lavouras. O horizonte coeso é uma característica pedogenética típica dos solos predominantemente cauliníticos, desenvolvidos de sedimentos terciários do grupo Barreiras e formações correlatas; não devem ser confundidos com fragipãs nem duripãs, os quais também têm forte coesão, mas têm pedogênese diversa (Ribeiro, 2001). Solos com caráter coeso têm sido reconhecidos em diversos países e são identificados como "hardsetting” (Mullins et al., 1987; 1990).

A caracterização dos solos quanto aos aspectos físicos e hídricos, é fundamental para a compreensão das inter-relações solo/água/planta/atmosfera, indispensáveis ao desenvolvimento adequado das plantas e elaboração de projetos de irrigação adequados ao meio ambiente.

Os horizontes coesos têm sido objeto de estudo nos últimos anos; no entanto não se possui completo entendimento de como manejá-los para maximizar a produtividade e longevidade das culturas. Estudos de natureza físico-hídrica em solos de tabuleiros costeiros foram iniciados na década de 1960, em Pernambuco, por Oliveira et al. (1968) e Oliveira
\& Melo (1970), seguindo-se o período de 1970 a 1980, em que poucos trabalhos foram produzidos. Nas décadas de 1990 e 2000, verificou-se uma retomada das investigações (Ribeiro, 1991; Cintra, 1997; Ribeiro, 2001; Araújo Filho, 2001; Nascimento, 2001; Libardi, 2002; Cintra et al., 2004), porém ainda há sérias dúvidas no que diz respeito à dinâmica da água no solo nesses tabuleiros com vistas a dar continuidade às pesquisas e racionalizar o manejo da irrigação no Platô de Neópolis. Diante o exposto, objetivou-se nesse trabalho determinar e utilizar os valores da densidade, porosidade, retenção de água e condutividade hidráulica na identificação e caracterização de horizontes coesos num argissolo amarelo distrófico dos tabuleiros costeiros do platô de Neópolis, SE.

\section{MATERIAL E MÉTODOS}

\section{Localização}

A pesquisa foi realizada no Distrito de Irrigação Platô de Neópolis, situado na região nordeste do Estado de Sergipe, na margem direita do Rio São Francisco, distando aproximadamente 110 km de Aracaju. O relevo da área do experimento é plano, típico dos Tabuleiros costeiros, apresentando declividade menor que $2 \%$; geograficamente, o Platô de Neópolis se encontra localizado entre os paralelos $10^{\circ} 17^{\prime}$ e $10^{\circ} 24^{\prime}$ de latitude Sul e entre os meridianos $36^{\circ} 35^{\prime}$ e $35^{\circ} 45^{\prime}$ de longitude Oeste de Greenwich, com altitude média de 110 m. A Figura 1 delimita a distribuição dos lotes que compõem o projeto Distrito de Irrigação do Platô de Neópolis e a localização do lote 24 , onde o experimento foi realizado.

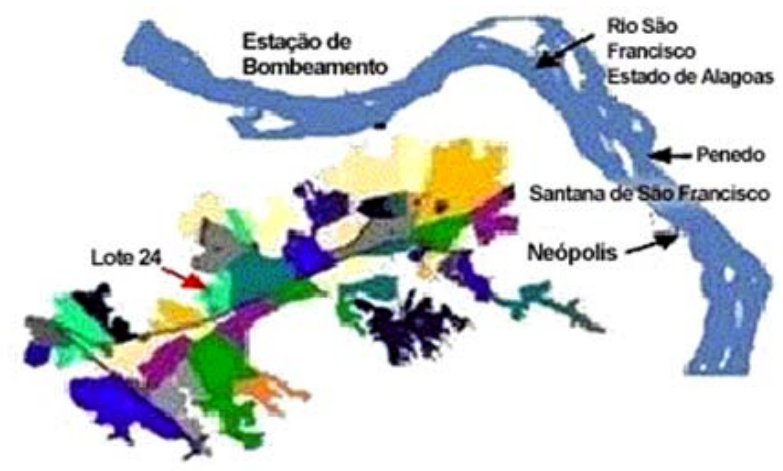

Figura 1. Localização do lote 24, no Distrito de irrigação Platô de Neópolis, $\mathrm{SE}$

\section{Clima e solo}

De acordo com a classificação de Köppen, o clima da área do Projeto é do tipo semi-úmido, com verão úmido e quente, altas incidências de radiação solar e elevado teor de umidade relativa do ar, durante todo o ano verificando-se, no entanto, dois períodos climáticos distintos, um de abril a setembro: estação chuvosa, e outro, de outubro a março, estação seca. Os maiores registros pluviométricos ocorrem no mês de junho com média de 262,6 mm e os menores no mês de novembro, com média de 63,3 mm. A temperatura média 
anual é em torno de $25^{\circ} \mathrm{C}$, sendo o mês de julho o mais frio, $18,6^{\circ} \mathrm{C}$ e o mês de dezembro o mais quente, $32,0^{\circ} \mathrm{C}$. A umidade relativa do ar é mais alta no mês de junho, 76,5\% e a velocidade do vento atinge seu valor máximo no mês de novembro, 3,4 $\mathrm{m} \mathrm{s}^{-1}$. O experimento foi conduzido, em um Argissolo Amarelo distrófico, com características similares as descritas por Holanda (2000).

Coletaram-se 09 amostras de solo com estruturas indeformadas, nas camadas $0,00-0,20 ; 0,20-0,40 ; 0,40-0,60$; $0,60-0,80 ; 0,80-1,00$ e $1,00-1,20 \mathrm{~m}$, das quais sete foram utilizadas para elaboração das curvas de retenção de água e as outras duas para determinação das outras características físicas do solo.

\section{Determinações}

Determinaram-se, de acordo com a metodologia proposta pela EMBRAPA (1997) a distribuição do tamanho das partículas, da densidade do solo e das partículas e a porosidade total.

Para se obter as curvas de retenção de água utilizaram-se as seguintes pressões pneumáticas: 1 ; 4; 10; 33; 100; 500 e $1500 \mathrm{kPa}$. Os equipamentos empregados foram o funil de placa porosa, para sucções de 1; 4 e $10 \mathrm{kPa}$; as câmaras de pressão de Richards de baixa tensão para os pontos 33 e $100 \mathrm{kPa}$ e as membranas de alta tensão para determinação dos pontos 500 e $1500 \mathrm{kPa}$. Ao final da aplicação das pressões, cujo momento era definido quando se constatava a completa ausência de drenagem nas câmaras de pressão, as amostras de solo eram secadas em estufa a $105^{\circ} \mathrm{C}$, durante $24 \mathrm{~h}$, para determinação do conteúdo de água, com base no solo seco. As curvas de retenção foram ajustadas obedecendo à metodologia proposta por van Genuchten (1980).

A condutividade hidráulica foi determinada pelo método dos perfis de umidade de Libardi (2002). O procedimento de campo utilizado foi o seguinte:

1) Delimitação de três áreas de inundação (repetições)

2) Instalação de três diques de folhas de zinco, com $1 \mathrm{~m}$ de altura por $5 \mathrm{~m}$ de diâmetro cravados no solo até a profundidade de $0,60 \mathrm{~m}$.

3) Instalação, em cada dique, de seis tensiômetros com manômetros de mercúrio nas profundidades 0,$1 ; 0,3 ; 0,5 ; 0,7$; 0,9; 1,1 m, para a medida do componente matricial do potencial total da água e posterior obtenção do teor volumétrico de água, a partir da curva de retenção. Os tensiômetros foram instalados aproximadamente no centro do dique, para assegurar que as mudanças dos potenciais medidas ocorreram no local em que o fluxo de água era vertical.

4) Saturação do solo até a profundidade de 1,1 m.

5) Cobertura do solo dentro do dique com uma camada de pó de serra

6) Cobertura do dique com um plástico preto

7) Obtenção de leituras diárias dos tensiômetros durante 47 dias.

Nas Figuras 2 e 3 mostra-se a construção dos diques no campo.

O método prevê a saturação do solo até que tenha sido estabelecido fluxo constante no perfil amostrado, condição que foi considerada satisfeita quando a leitura do tensiôme-

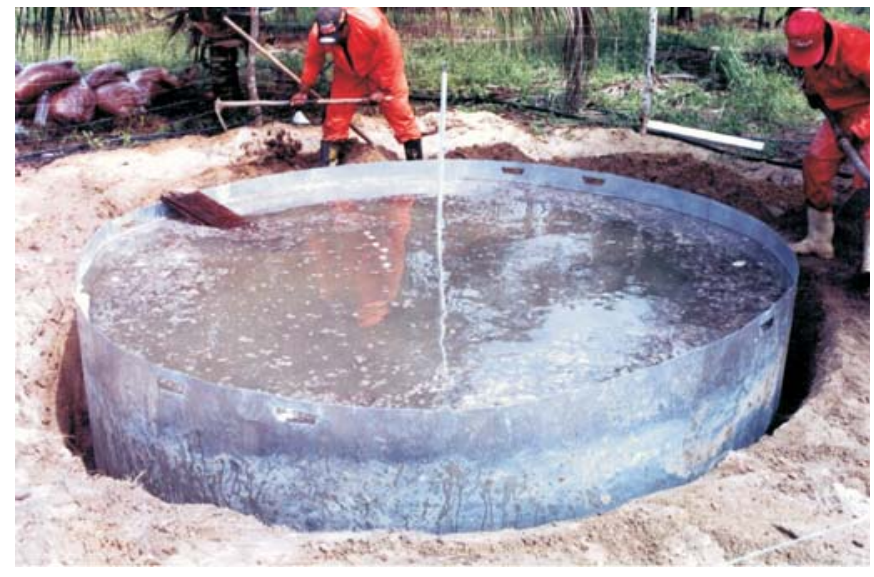

Figura 2. Inundação da área delimitada pelo dique até a saturação total do perfil do solo

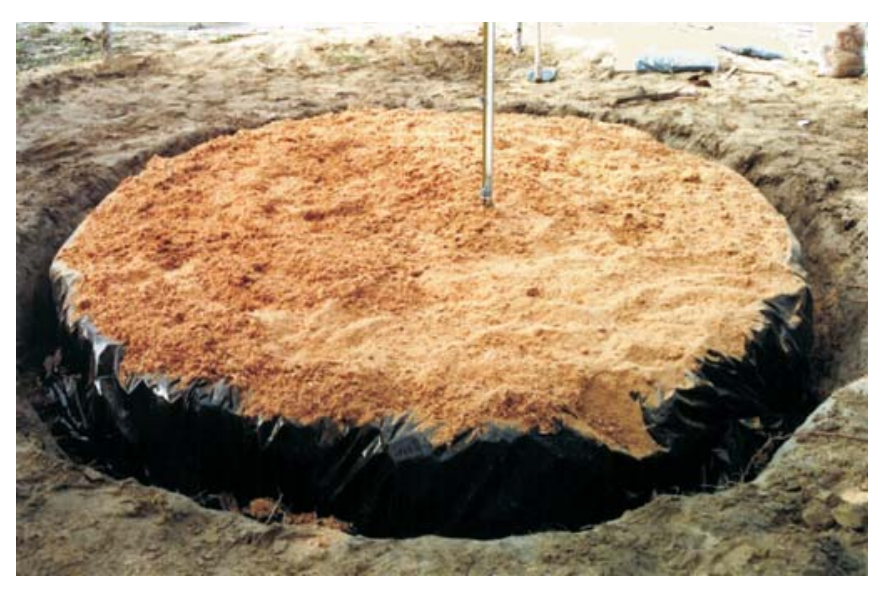

Figura 3. Colocação de pó de serra sobre uma lâmina de plástico preto e instalação de tensiômetros para medida do componente matricial do potencial da água no solo

tro colocado a $1,1 \mathrm{~m}$ se tornou constante; neste momento, o fornecimento de água foi interrompido e a área coberta com uma dupla camada de plástico preto envolvendo pó de serra e material isolante térmico, para atendimento das condições de contorno do método as quais prevêem completa ausência de evaporação e de entrada de água através da superfície (Figura 3).

O conjunto de tensiômetros foi ligado por tubos de nylon com 0,002 m de diâmetro e comprimento variável, a uma única cuba de acrílico presa a uma haste de alumínio na qual as leituras da altura da coluna de mercúrio foram efetuadas (Figura 3). O cálculo do componente matricial ( $\Psi \mathrm{m})$ foi feito com base na equação:

$$
\Psi \mathrm{m}=-12,6 \mathrm{~h}+\mathrm{hc}+\mathrm{z}
$$

em que:

$$
\begin{aligned}
& \text { h - leitura em cm de Hg } \\
& \text { hc - altura da superfície do Hg no manômetro com } \\
& \text { relação à superfície do solo } \\
& \text { z - profundidade da cápsula porosa com relação à } \\
& \quad \text { superfície do solo }
\end{aligned}
$$

Para o cálculo de $K(\theta)$ por meio dos perfis de umidade 
descrito por Libardi et al. (1980) utilizou-se a seguinte expressão:

$$
K(\theta)=\text { Ko e } \gamma(\theta-\theta 0)
$$

Em que Ko e $\theta$ o são a condutividade hidráulica e o conteúdo de água do solo no tempo zero de redistribuição, $\theta$ conteúdo de água atual do solo para determinada profundidade e $\gamma$ uma constante, adimensional.

Para se conhecer $\gamma$ e Ko mediu-se $\theta$ desde a superfície do solo até a profundidade de $1,1 \mathrm{~m}$, durante aproximadamente 30 dias e se construiu o gráfico $\theta o-\theta$ versus ln t para cada profundidade. Os coeficientes angular e linear de cada curva estão de acordo com Libardi (1980) igual a $1 / \gamma$ e Ko, respectivamente.

O método se baseia na relação exponencial existente entre $\mathrm{K}(\theta)$ e o conteúdo de água no solo, hipótese considerada válida visto que, normalmente, ela quase sempre apresenta alto coeficiente de correlação (Sisson et al.,1980; Chong et al., 1981; Bacchi \& Reichardt, 1988; van Lier \& Libardi, 1999).

\section{RESULTADOS E DISCUSSÃO}

\section{Características fisico-hídricas dos solos}

A Tabela 1 apresenta algumas características físicas do solo, podendo-se observar o caráter essencialmente arenoso do solo, embora a partir dos $40 \mathrm{~cm}$ o solo apresente textura mais fina, passando de areia franca para franco-arenoso.

A densidade do solo foi o principal atributo físico utilizado na avaliação de camada coesa. Por meio dela observou-se que o solo possui camadas de caráter coeso, conforme apresentado no intervalo 0,20 a $0,40 \mathrm{~m}\left(1,71 \mathrm{~kg} \mathrm{dm}^{-3}\right)$, e no intervalo de profundidade de 1,00 a 1,20 m com densidade $1,69 \mathrm{~kg} \mathrm{dm}^{-3}$. Resultado situação similar foi descrita por Cintra (1997), na região Tabuleiro Sul de Sergipe. Camadas adensadas alternadamente no perfil do solo podem formar uma zona de acumulação de água, à sua montante, capaz de criar situações diferenciadas na disponibilidade hídrica e no arejamento às plantas. A densidade das partículas do solo, pela sua própria natureza, não varia significativamente com a profundidade destacando-se valores bem próximos de $2,65 \mathrm{~g} \mathrm{~cm}^{-3}$, valor aceito como média universal para os solos minerais, pela Sociedade Internacional da Ciência do Solo.

O menor valor da porosidade na camada de 0,20 a 0,40 m resulta do adensamento desta camada e a redução do volume total de poros decorre do caráter coeso dessas camadas nos Tabuleiros Costeiros.
As curvas de retenção de água apresentadas na Figura 4 são típicas de solos arenosos, em que o conteúdo de água do solo é reduzido abruptamente entre 0 e $10 \mathrm{kPa}$.

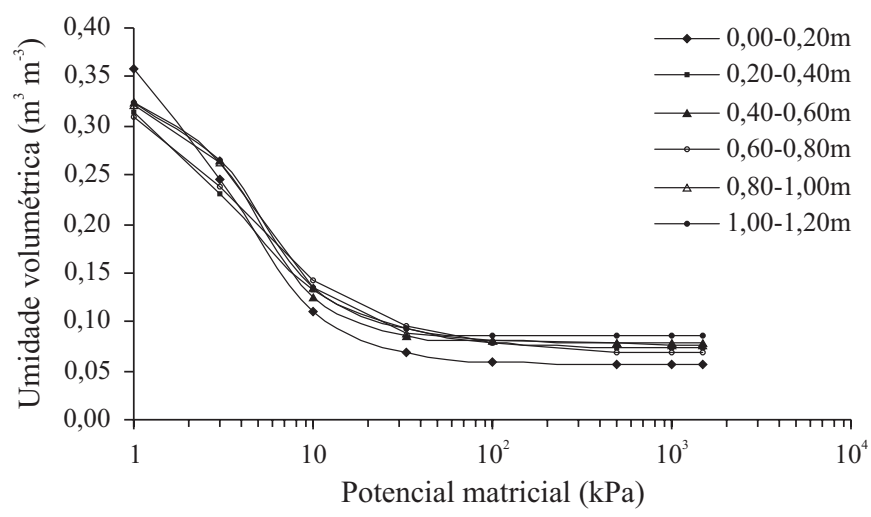

Figura 4. Curvas de retenção de água do solo

A partir dos dados do componente matricial, e se considerando a referência gravitacional na superfície do solo, calcularam-se os valores de potencial total, os quais foram ajustados em função da profundidade para diversos tempos de redistribuição a uma equação exponencial. Na Figura 5 apresentam-se alguns perfis de potencial total com seus respectivos coeficientes de determinação $\mathrm{R}^{2}$ variando entre 0,88 a 0,93. Em virtude dos bons ajustamentos, é alta a confiabilidade dos valores dos gradientes hidráulicos calculados.

A correlação exponencial encontrada entre o potencial total da água no solo e a profundidade no processo de redistribuição de água, utilizada para calcular o gradiente hidráulico

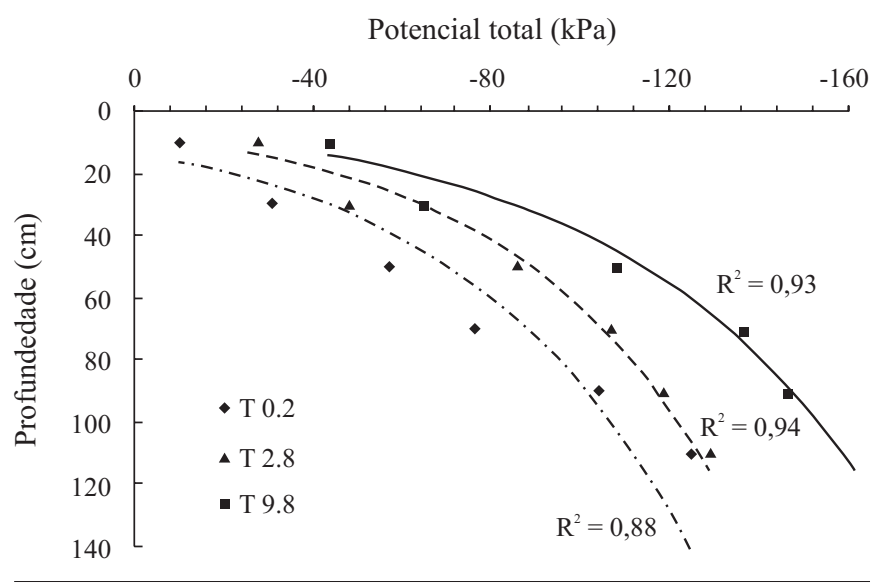

Figura 5. Curvas de ajuste do potencial total da água no solo em função da profundidade para três tempos de distribuição de água no solo

Tabela 1. Características físicas do solo da área experimental

\begin{tabular}{|c|c|c|c|c|c|c|c|}
\hline $\begin{array}{l}\text { Intervalo de prof. } \\
\text { (m) }\end{array}$ & $\begin{array}{c}\text { Areia } \\
\left(g_{\text {kg-1) }}^{-1}\right)\end{array}$ & $\begin{array}{c}\text { Silte } \\
\left(g_{\text { kg-1) }}^{-1}\right)\end{array}$ & $\begin{array}{l}\text { Argila } \\
\left(g \mathrm{~kg}^{-1}\right)\end{array}$ & $\begin{array}{l}\text { Classificação textural } \\
\text { (USDA) }\end{array}$ & $\begin{array}{c}\text { Ds } \\
\left(\mathrm{kg} \mathrm{m}^{-3}\right)\end{array}$ & $\begin{array}{c}\text { Dp } \\
\left(\mathrm{kg} \mathrm{m}^{-3}\right)\end{array}$ & $\begin{array}{l}\text { Porosidade total } \\
\left(\mathrm{m}^{3} \mathrm{~m}^{-3}\right)\end{array}$ \\
\hline $0,00-0,20$ & 892,11 & 50,23 & 57,66 & Areia & 1,63 & 2,60 & 0,37 \\
\hline $0,20-0,40$ & 863,32 & 51,44 & 85,24 & Areia Franca & 1,71 & 2,63 & 0,35 \\
\hline $0,40-0,60$ & 831,88 & 65,30 & 102,82 & Franco Arenoso & 1,68 & 2,65 & 0,37 \\
\hline $0,60-0,80$ & 793,31 & 86,29 & 120,40 & Franco Arenoso & 1,66 & 2,63 & 0,37 \\
\hline $0,80-1,00$ & 771,44 & 98,15 & 130,41 & Franco Arenoso & 1,65 & 2,65 & 0,38 \\
\hline $1,00-1,20$ & 755,44 & 111,59 & 132,98 & Franco Arenoso & 1,69 & 2,68 & 0,37 \\
\hline
\end{tabular}


corrobora os resultados encontrados recentemente por van Lier \& Libardi (1999) que trabalhando com 12 pontos de observação em uma Terra Roxa Estruturada, também obtiveram bom ajuste $\left(\mathrm{R}^{2}>0,90\right)$ a uma equação exponencial.

Na Figura 6 apresenta-se o gráfico $\theta o-\theta$ versus $\ln t$ para cada profundidade.

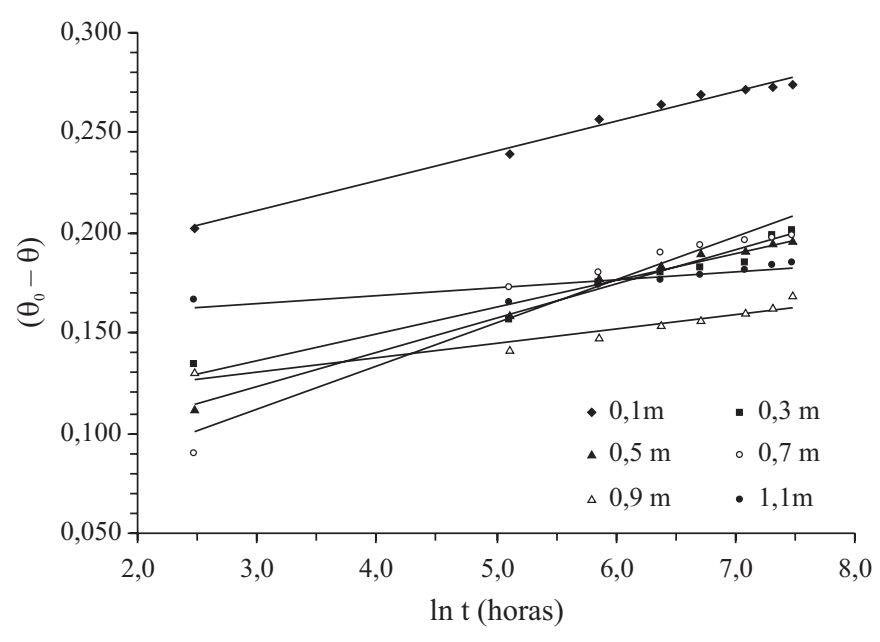

Figura 6. Curvas de $(\theta o-\theta)$ em função do In t para cada profundidade

Na Figura 7 apresenta-se a condutividade capilar em função do conteúdo de água no solo para os intervalos de profundidade estudados; nota-se que as curvas possuem comportamento exponencial e a condutividade capilar aumenta com o conteúdo de água do solo, comportamento coerente com o constatado por Guerra (2000), Antonino et al. (2001) e Carvalho (2002); verifica-se, também, que não existe, entre as diferentes profundidades de solo, uma relação unívoca entre $\theta$ e $K(\theta)$.

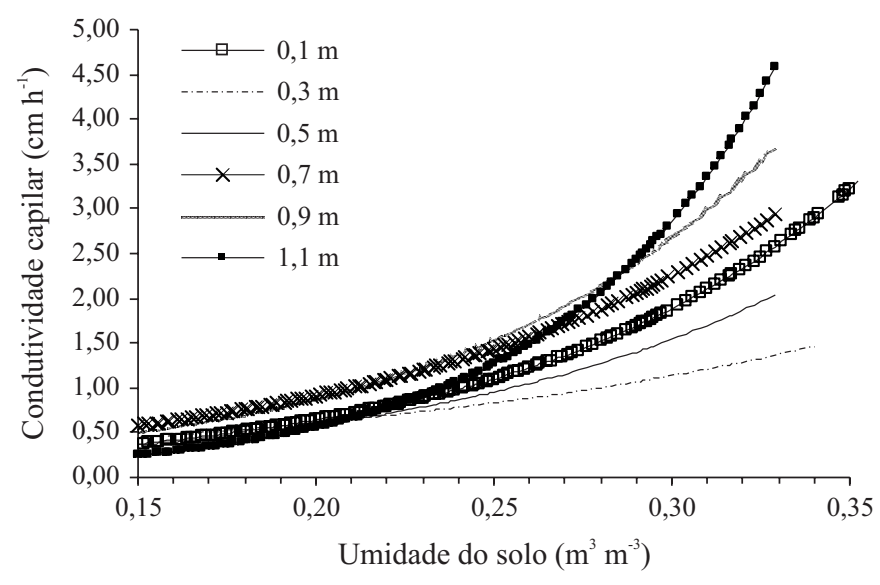

Figura 7. Condutividade hidráulica capilar em função do teor de água do solo em seis profundidades

Pode se observar pela Figura 7, a tendência da condutividade hidráulica capilar do solo aumentar com a profundidade. Resultado idêntico foi obtido por Carvalho et al. (1996) em um Latossolo Roxo Distrófico e por Aragão Júnior et al. (1983) em um Podzólico Vermelho-Amarelo.
Cadima et al. (1980) trabalhando em um Latossolo Vermelho-Amarelo encontraram que a variabilidade da condutividade capilar no sentido vertical foi muito pronunciada salientando, assim, que o uso de valores médios de condutividade capilar pode trazer erros consideráveis na estimativa do fluxo de água no solo.

Observa-se, ainda na Figura 7, que as menores condutividades capilares foram encontradas na camada 0,20-0,40 m para conteúdos de água acima de $0,22 \mathrm{~m}^{3} \mathrm{~m}^{-3}$ e para a camada 1,00-1,20 m, situações relacionadas, provavelmente, aos altos valores da densidade do solo e baixas porosidades totais dessas camadas, como mostrado na Tabela 1; referidas condições revelam o caráter coeso do solo nesses intervalos de profundidade.

A metodologia utilizada para a delimitação da parcela experimental (chapa de zinco cravada até a profundidade de 0,60 m no solo) permitiu um perfeito confinamento do solo em uma área relativamente pequena conferindo, com segurança, o movimento vertical da água exigido pelo método. Valores discrepantes de Potencial Total certamente podem ocorrer se esta condição não for devidamente considerada.

\section{CONCLUSÕES}

1. Os atributos físicos estudados (densidade, porosidade, retenção da água do solo e condutividade capilar) se expressaram adequados à identificação das camadas coesas do solo.

2. Os atributos físicos e hídricos do solo estudados permitiram uma melhor caracterização das camadas coesas no solo

3. Utilizando-se o método do perfil instantâneo e se tendo especial cuidado na delimitação da área para inundação do perfil do solo, o modelo de Libardi permitiu determinar a condutividade capilar do solo.

\section{LITERATURA CITADA}

Antonino, C. D; Jaramillo, R. A.; Sousa, E. S. de; Maciel Netto, A.; Carneiro, J. G.; Montenegro, A. A. A. Determinação da condutividade hidráulica e da sorvidade de um solo com infiltrômetro a disco. Revista Brasileira de Engenharia Agrícola e Ambiental, Campina Grande, v.5, n.2, p.247-253, 2001.

Araújo Filho, J. C. de. Investigações preliminares sobre a pedogênese de horizontes coesos em solos dos tabuleiros costeiros do Nordeste do Brasil. In: Cintra, F. L. D.; Anjos, J. L. dos; Ivo, W. M. P. (org.) Workshop Coesão em Solos dos Tabuleiros Costeiros, 2001, Aracaju. Anais... Aracaju: Embrapa Tabuleiros Costeiros, 2001, p.123-139.

Aragão Júnior, T. C. A.; Magalhães, C. A.; Castro, P. T. Determinação da condutividade hidráulica em um podzolico-vermelhoamarelo em condições de campo. Pesquisa Agropecuária Brasileira, Brasília, v.18, n.7, p.805-810, 1983.

Bacchi, O. O. S. Reichardt, K. Escalonamento de propriedades hídricas na avaliação de métodos de determinação da condutividade hidráulica de solos. Revista Brasileira de Ciência do Solo, Campinas, v.12, n.3, p.217-223, 1988. 
Cadima, Z. A.; Libardi, P. L.; Reichardt, K. Variabilidade espacial da condutividade hidráulica em um Latossolo Vermelho-Amarelo textura média, no campo. Revista Brasileira de Ciência do Solo, Campinas, v.4, n.1, p.63-66, 1980. 89p.

Carvalho, L. A. de. Condutividade hidráulica do solo no campo: simplificações do método do perfil instantâneo, Piracicaba: ESALQ/USP, 2002, 89p. Dissertação Mestrado

Carvalho, L. G. de; Sampaio, S. C.; Silva, A. M. Determinação da condutividade hidráulica "in situ" de um Latossolo Roxo Distrófico. Engenharia Rural, Piracicaba, v.7, n.1, p.1-97. 1996.

Chong, S. K.; Green, R. E.; Ahuja, L. R. Simple in situ determination of hydraulic conductivity by power-function description of drainage. Water Resources Research. Washington, v.17, p.1109-1114, 1981.

Cintra, F. L. D. Disponibilidade de água no solo para porta-enxertos de citros em ecossistema de Tabuleiro Costeiro. Solos e nutrição de plantas. Piracicaba: ESALQ/USP. 1997. 90p. Tese Doutorado

Cintra, F. L. D.; Portela, J. C.; Nogueira, L. C. Caracterização física e hídrica em solos dos Tabuleiros Costeiros no Distrito de Irrigação Platô de Neópolis. Revista Brasileira de Engenharia Agrícola e Ambiental, Campina Grande, v.8, n.1, p.45-50, 2004.

EMBRAPA - Empresa Brasileira de Pesquisa Agropecuária, Centro Nacional de Levantamento e Conservação do Solo, Manual de métodos de análises de solo. Rio de Janeiro: Embrapa Solos. 1997. 212p.

Guerra, H. O. C. Física dos solos. Campina Grande: UFPB. 2000. 175p.

Holanda, F. S. R. Estudo integrado do Vale do São Francisco Sergipano: Região de Tabuleiros Costeiros e Pediplano Sertanejo - Pedologia/Francisco Sandro Rodrigues Holanda. Aracaju: 2000. 138p.

Jacomine, P. K. T. Distribuição geográfica, características e classificação dos solos coesos dos tabuleiros costeiros. In: Reunião Técnica sobre Solos Coesos dos Tabuleiros Costeiros. Pesquisa e desenvolvimento para os tabuleiros costeiros, 1996. Cruz das Almas. Anais... Aracajú: Embrapa CPATC/Embrapa CNPMF/EAUFBA/IGUFBA, 1996. 80p.

Libardi, P. L., Dinâmica da água nos solos de tabuleiro. In: Araújo, Q. R. de. (org.). 500 anos de uso do solo no Brasil. Ilhéus: UESC, 2002. p.581-596.
Libardi, P. L.; Reichardt, K.; Nielsen, D. R.; Biggar, J. W. Simple field methods for estimating hydraulic conductivity. Soil Science Society America Journal, Madison, v.44, p.3-7, 1980.

Mullins, C. E.; McLeod, D. A.; Northcote, K. H.; Tisdall, J. M.; Young, I. M. Hardsetting soils: Behavior, occurrence and management. Advances in Soil Science, New York, v.11, p.37-108, 1990.

Mullins, C. E.; Young, I. M.; Benghough, A. G.; Ley, G. J. Hardsetting soils. Soil use and management, Australian Journal of Soil Research, Clayton South, v.3, p.79-83, 1987.

Nascimento, G. B. do. Caracterização dos solos e avaliação de propriedades edáficas em ambientes de tabuleiros costeiros da região Norte Fluminense, RJ. Rio de Janeiro: UFRJ. 2001, 162p.

Oliveira, L. B. de; Dantas, M. S.; Campelo, A. B.; Galvão, S. S.; Gomes, I. F. Caracterização de adensamento no subsolo de uma área de tabuleiro da Estação Experimental do Curado. Pesquisa Agropecuária Brasileira, Brasília, v.3, n.3, p.207-214, 1968.

Oliveira, L. B. de.; Melo, V. de. Caracterização físico-hídrica do solo. I. Unidade de Itapirema. Pesquisa Agropecuária Brasileira, Brasília, v.5, n.1, p.35-48, 1970.

Rezende, J. de O. Solos coesos dos Tabuleiros Costeiros: limitações agrícolas e manejo. Salvador: SEAGRI, 2000. 117p. Serie de Estudos Agrícolas, 1.

Ribeiro, L. P. Premiers resultas sur la génese des sols a horisons indures dans la region du Cruz das Almas, BA, Brésil. In: Table Ronde sur lórganization et dinamique interne de la couverture pedologique. Caen: CNRS, 1991, 99p.

Ribeiro, M. R. Características morfológicas dos horizontes coesos dos solos dos Tabuleiros Costeiros. In: Cintra, F. L. D; Anjos, J. L. dos; Ivo, W. M. P. de M. Workshop Coesão em Solos dos Tabuleiros Costeiros, 2001, Aracajú. Anais... Aracaju: Embrapa Tabuleiros Costeiros, 2001. p.161-168.

Sisson, J. B.; Ferguson, A. H; van Genuchten, M. T. Simple method for predicting drainage from field plots. Soil Science of American Journal, Madison, v.44, n.6, p.1147-1152. 1980.

van Genuchten, M. T. A closed-form equation for predicting the hydraulic conductivity of unsaturated soils. Soil Science Society of American Journal, Madison, v.44, n.5, p.892-898, 1980.

van Lier, Q. J.; Libardi, P. L. Variabilidade dos parâmetros da equação que relaciona a condutividade hidráulica com a umidade do solo no método do perfil instantâneo. Revista Brasileira de Ciência do Solo, Viçosa, v.23, n. 23, p.1005-1014, 1999. 